\title{
The urological complications of vaginal birth after cesarean (VBAC) - a literature review
}

\author{
Valentin Nicolae Varlas ${ }^{1,2}$, Yassin Rhazi ${ }^{1}$, Roxana Georgiana Bors ${ }^{1}$, Ovidiu Penes ${ }^{3 *}$, Daniel Radavoi ${ }^{4}$
}

\section{Author Affiliations:}

1. Department of Obstetrics and Gynaecology, Filantropia Clinical Hospital, Bucharest, Romania

2. Department of Obstetrics and Gynaecology, Carol Davila University of Medicine and Pharmacy, Bucharest, Romania

3. Department of Anesthesiology and Intensive Care, Bucharest Emergency University Hospital, Bucharest, Romania

4. Department of Urology, Prof. Dr. Theodor Burghele Clinical Hospital, Bucharest, Romania

\author{
* Corresponding Author: \\ Ovidiu Penes, \\ Department of Anesthesiology \\ and Intensive Care, Bucharest \\ Emergency University Hospital, \\ Bucharest, Romania. \\ E-mail: ovidiu.penes@umfcd.ro
}

\section{DOI}

10.25122/jml-2021-0219

\section{Dates}

Received: 15 May 2021

Accepted: 22 July 2021

\section{ABSTRACT}

The appearance of urological complications is a major problem in obstetrics and gynecologic surgery; the bladder is the most common damaged organ. Due to a continuous increase in the rate of cesareans, the incidence of urologic complications will be potentially higher. We reviewed the most important risk factors for urinary tract injury and analyzed the strategies necessary to avoid these situations during vaginal birth after cesarean (VBAC). The risks and benefits of VBAC should be balanced before deciding the mode of delivery.

KEYWORDS: VBAC, urological complications, uterine rupture, bladder rupture, ureteral lesion.

\section{INTRODUCTION}

Studies have shown that vaginal birth after low transverse cesarean section is considered safe and effective [1]. According to the Centers for Disease Control and Prevention (CDC), VBAC rates from the entire number of births increased from $12.4 \%$ in 2016 to $13.3 \%$ in 2018 [2]. After a previous cesarean section, the percentage of vaginal births in women who desired a VBAC is about 60-80\% [3]. Due to the increased risk of uterine rupture, the induction of labor on the scarred uterus is controversial in the literature. Maternal and fetal complications can occur much more frequently during labor in the case of VBAC [4-6].

Every year, we are observing an increasing trend of cesarean deliveries, and the attention is focused on long-term complications. The increase in primary cesarean deliveries leads to a higher number of repeated cesarean deliveries [7]. In recent years, studies have shown a continuous increase in births by cesarean section; Romania is currently in first place in Europe with a rate of 46.9\% [8]. The regulatory organizations are trying to compensate by promoting vaginal birth after cesarean section (VBAC), which is in its infancy in less developed countries. Achieving this goal is hampered by several restrictions on the reluctance of both physicians and patients regarding VBAC [9]. Despite this, VBAC was considered by many patients a good method to avoid repeated cesarean deliveries [10]. Attanasio et al. reported that at 12 months postpartum, $45 \%$ of women who gave birth by cesarean section want to experience VBAC for a future birth. Statistics prove the opposite by the fact that only about $12 \%$ would try VBAC [11].

Trial of labor after cesarean (TOLAC) is a planned or tried VBAC, being a safe option for many women in trying to reduce cesarean birth after cesarean (CBAC) [9]. 


\section{JOURNAL of MEDICINE and LIFE}

\section{TOLAC - BETWEEN RISK AND BENEFITS}

TOLAC is associated with a success rate ranging from $65 \%$ to $85 \%$ [12-14]. The rate of success depends on the previous indication for cesarean section (it is higher when the previous cesarean is done for malpresentation, gestational hypertension, or when the patient has a previous vaginal birth and may be lower when the cesarean is done for dystocia, diabetes, failure to progress or cephalopelvic disproportion) [15].

According to international guidelines (the American College of Obstetricians and Gynecologists - ACOG, Royal College of Obstetricians and Gynaecologists - RCOG, Le Collège National des Gynécologues et Obstétriciens Français - GNGOF), TOLAC should be taken into account in those medical units that have facilities regarding the management of unpredictable situations that may occur following a uterine rupture, and that may endanger the mother and fetus [16-18].

The main risk of TOLAC is uterine rupture which occurs in $0.2-0.9 \%$ of women with one previous C-section [10, 17, 19]. Uterine rupture was associated with maternal mortality in less than $1 \%$ of cases and perinatal mortality in 3 to $6 \%$ of cases [17]. The main risk factors of uterine rupture during TOLAC are an unknown previous uterine incision, an interpregnancy interval $<12$ months, poor wound healing of a previous uterine scar, and a prior preterm cesarean delivery [20].

Uterine rupture is an obstetrical emergency, causing an increased risk of fetal demise and severe maternal outcomes such as bladder and ureteral injury, especially when the patients are not well selected for VBAC [10]. Antepartum ultrasound evaluation of the uterine scar is insufficiently predictive of uterine rupture. Some authors report that a distance of 3.1 to $5.1 \mathrm{~mm}$ from the bladder wall to the amnion has a $96 \%$ sensitivity and a $63 \%$ specificity for the occurrence of a uterine defect (dehiscence, rupture). There is insufficient evidence to recommend the routine ultrasound assessment of uterine scar integrity [21, 22]. The cut-off value for the thickness of the uterine scar on the lower uterine segment measured by transvaginal sonography is not established. A thickness of the lower uterine segment less than $2.3 \mathrm{~mm}$ is correlated with an increased risk of uterine and urinary bladder rupture during TOLAC [23, 24].

The benefits of successful TOLAC derive from avoidance of the complications associated with cesarean delivery (immediate risks such as wound complications, injury to pelvic organs, and long-term risks such as abnormal placentation, uterine rupture, cesarean scar pregnancy, incisional endometriosis or adhesions) [10]. In pregnant women with a prior cesarean section (CS) with premature rupture of membranes (PROM), the induction of labor was observed to be accompanied by a double risk of uterine rupture and risk three times higher compared to the spontaneous initiation of labor [25].

\section{VBAC AND UROLOGICAL COMPLICATIONS}

Uterine rupture is associated with the possible risk of bladder and ureteral injury [1]. The incidence of bladder injury associated with uterine rupture has a significant variability between $8 \%$ and $15 \%[3,26]$. The highest percentage is found after a failed VBAC trial [27]. Cahill et al. did not found any statistical difference regarding bladder lesions between VBAC and elective cesarean section $(0.44 \%$ vs. $0.42 \%$ ) [28]. Few cases of simultaneous rupture of the uterus and bladder at birth have been described [29, 30]. The clinical picture is diverse and includes hematuria (the most frequent symptom), severe lower abdominal pain, vaginal bleeding, palpation of fetal parts, cessation of uterine contractions, a non-reassuring fetal status, and maternal shock [31]. Other less common signs are vernixuria, oligo-anuria, and the presence of meconium in the urine [25, 29].

Urinary incontinence (stress urinary incontinence, urgency urinary incontinence, and mixed types of incontinence) was observed after vaginal delivery. Pregnancy itself is a risk factor for incontinence. Vaginal delivery has a major impact on the pelvic floor, weakening bladder neck support and affecting innervation [26]. It is estimated that approximately $12 \%$ of women report significant symptoms from stress incontinence and $8 \%$ from urgency incontinence. The risk of stress urinary incontinence is almost 2 times higher in women who delivered vaginally, with an increase in the absolute risk of $8 \%$ compared to cesarean section. The effect is more important in younger women as they have a longer life expectancy. The absolute risk of urgency incontinence is higher in women who deliver vaginally, with an increase of $3 \%$ compared to cesarean section [32].

We observed a heterogeneous incidence of bladder injuries during gynecological procedures compared to obstetric procedures. Some authors revealed a higher incidence in gynecologic interventions, and others showed the contrary. Thus, studies revealed an incidence of $0.49 \%$ for bladder injury, $0.24 \%$ for ureteral lesions in gynecological surgery, and $0.07-0.18 \%$ for bladder and $0.01-0.027 \%$ for ureter injury in obstetric surgery $[23,33,34]$.

Bladder injury during cesarean section is reported in approximately 0.08 to $0.94 \%$ of cases [3]. When the rupture location was at the level of the uterine scar, characterized by poor vascularization, the hemorrhage did not occur. When CS is performed in the second stage of labor, the risk of incidental cystotomy is higher compared to the first stage of labor. In the particular case of a failed TOLAC, bladder injury was seen more often than in the control group ( $64 \%$ versus $22 \%$, respectively) [3]. A higher rate of bladder ruptures is quickly recognized intraoperative and subsequently repaired with a significant decrease in patient morbidity [3].

Potential consequences of bladder injury include prolonged operative time, urinary tract infection, prolonged use of a bladder catheter, and vesicouterine or vesicovaginal fistula formation [3]. Long-term consequences of VBAC include an increased risk for urinary incon- 


\section{JOURNAL of MEDICINE and LIFE}

tinence compared with nulliparous women or patients who underwent cesarean sections [10]. A thorough selection of the patients who can deliver vaginally after cesarean section may reduce, but not entirely cancel, some of these risks [35].

Existing data suggest that the presence of a prior cesarean delivery is associated with a 4-fold increased risk of bladder injury compared with a primary cesarean delivery. The incidence of bladder injury is higher in the group of patients who are subjected to emergency cesarean (careful dissection is not always a priority when attempting a fast delivery of a distressed fetus) and in the presence of uterine rupture [10]. Simultaneous uterine rupture and bladder injury are found in approximately $14 \%$ of cases [3]. After VBAC, Lua et al. showed a laparoscopic repair of uterine rupture using a two-layer technique simultaneous with rupture of the posterior bladder using a two-layer closure [36].

There are several other apparent risk factors for bladder injury at the moment of the cesarean section, such as age (bladder injury appears to be more frequent in older women), parity (bladder injury seems to be more frequent with increased parity), body mass index, adhesions, station of the presenting fetal part, time from skin incision to uterine incision, and estimated blood loss [31, 37]. The presence of adhesions in the abdominal cavity, particularly those between the bladder and the lower uterine segment, is associated with an increased risk of bladder injury during surgery (most bladder injuries occur during bladder dissection) [10]. Approximately 60\% of patients with bladder injury had adhesions caused by a prior cesarean delivery compared with $10 \%$ in the control group. The density of intra-abdominal adhesions after cesarean is increasing and is related to the number of cesareans. Thus, the adhesion rates vary from $12-46 \%$ in patients with two CSs to $26-75 \%$ in those with three CSs [38, 39]. Risk factors for the development of adhesions include infection, excessive manipulation of tissue, increased blood loss during surgery, and tissue ischemia.

Most iatrogenic ureteral injuries are incomplete transection, but perforation (partial or complete), ligation, or complete transection can also occur. One review reported that $38 \%$ of ureteral injuries are initially missed. Long-term complications of missed ureteral injuries include urinoma, ileus, periureteral abscess, sepsis, ureteral fistula, or ureteral stricture [20].

A possible explanation for bladder-ureteral lesions may be the rupture of dense adhesions between the bladder and uterus, by high peritonization during the previous cesarean section, by an incongruence of the edges in multiple scarred uterus or associated endometriosis lesions [33, 40, 41]. Sharma et al. described a rare complication of uterine rupture associated with bladder rupture and ureter avulsion after vacuum-assisted VBAC [42]. Surgical conduct in such situations can be conservative (repair) or radical (hysterectomy).

Long-term complications of urinary tract injuries include urogenital fistulas. Obstetric fistulas are rare, most cases being identified after instrumental vaginal birth or in the case of manual extraction of the placenta. Most vesicouterine and vesicovaginal fistulas occur after cesarean section and uterine rupture. Postoperative urogenital fistula occurs due to direct lesions during dissection, being recognized during surgery and successfully repaired in most cases. Other possible causes of urogenital fistulas include injury by gripping or crushing, cauterizing, or kinking. In these cases, the blood supply to the tissues affected by necrosis should be reduced. The fistula may become symptomatic from days to months after surgery $[43,44]$.

Bladder injury must be recognized and repaired. Extravasation of urine into the peritoneal cavity causes peritonitis, ileus, and if prolonged, can lead to abdominal sepsis. Bladder injuries (intraperitoneal, extraperitoneal) are repaired using a two-layer technique. The first layer is closed with a running 3-0 absorbable suture. The second layer is closed using a running 2-0 or 3-0 absorbable suture. Urethral catheter drainage is recommended for two to three weeks. Prolonged bladder catheterization exposes the patient to an increased risk of urinary tract infection. The remains of the bladder, ureters, and bladder neck should be examined to exclude concomitant injury. Administration of agents that color the urine can assess the integrity of the lower urinary tract. A cystogram is done before catheter removal to evaluate healing. Other surgeons use one-layer sutures for cystotomies $<2 \mathrm{~cm}$ and two layers for larger cystotomies. The bladder is epithelialized in three to four days and regains its normal function after 21 days. Additional antibiotic prophylaxis is not required when a urinary tract injury occurs, whether it is recognized intra- or postoperatively. Supratrigonal injuries are usually repaired with excellent results if they are recognized intraoperatively. On the other hand, injuries to the trigone or below the trigone may involve the ureters or urethra and are more challenging to repair than injuries at the level of the bladder dome or above the trigone. Exposure and suturing of this area are complex, and ureteral stent placement may be associated $[3,40]$.

During surgery, the most commonly used approach for ureteral lesions is to repair them by ureteroureterostomy or ureteroneocystostomy. It is preferable to perform ureteroureterostomy without a live anastomosis. The usual recommendation is to insert a ureteral stent following any repair that was performed. Ureteral lesions occur most frequently in the lower portion near the ureterovesical junction, ureteral anastomosis being possible if the lesion is located more than $3 \mathrm{~cm}$ from the ureterovesical junction. If the ureteral lesion is at a distance that is less than or equal to $2 \mathrm{~cm}$ from the ureterovesical junction, primary reconstruction is difficult, and reimplantation of the ureter (ureteroneocystostomy) is recommended [23].

\section{DISCUSSION}

It is difficult to evaluate the incidence of bladder and ureteral injuries after VBAG because there are few studies with no clinical trials. However, the low incidence of bladder and ureteral injury correlates to obstetricians' expertise of a tertiary center that encouraged VBAC. Another factor is represented by the level of training of obstetricians, some of whom also perform gynecologic oncology procedures. 


\section{JOURNAL of MEDICINE and LIFE}

Instead, the wrong selection of cases for TOLAC, intraoperative speed, history of cesarean section, fibroids, and endometriotic foci may increase the risk of injury of the bladder and ureters. In bladder lesions, the topography of the lesion is significant both in terms of its intraoperative resolution and long-term recovery. The ureteral injuries that might occur during cesarean result from intraoperative difficulty to control heavy bleedings from an anterior placenta site, a focal adherent placental tissue, an extension of the incision into the broad ligament, or blind hemostatic sutures. In very few cases, it's possible to damage the ureter directly following an iatrogenic extension of hysterotomy.

A higher incidence of left ureter damage was observed due to its anterior exposure by dextrorotation of the pregnant uterus [34]. Other author revealed no significant differences between the ureters regarding injury risk [20]. However, a study by Eisenkop and Rajasekar does not support this concept [23].

Because forensic reports showed frequent urinary tract injuries in recent years, the involvement of a urologist is essential to resolve ureteral injuries in particular.

Infant morbidity and mortality may be affected by the mode of delivery. Studies show that the infant mortality rates are higher in the case of TOLAC compared to repeated cesarean section (perinatal mortality rate of 0.13 versus 0.05 percent; neonatal mortality rate of 0.11 versus 0.06 percent). On the other hand, transient tachypnea of the newborn is more common in the case of repeated cesarean section compared with TOLAG (4.2 versus 3.6 percent, respectively) [45].

Counseling women with a prior cesarean section regarding the possibility of a vaginal birth should weigh its success in relation to potential maternal-fetal risks.

\section{CONCLUSIONS}

Urinary tract complications are uncommon during the trial of labor after cesarean but carry the risk of serious morbidity. The risks and benefits of vaginal birth after cesarean should be balanced before deciding the mode of delivery. Both cesarean section and vaginal delivery are associated with the risk of urinary injuries. Vaginal delivery is more frequently associated with long-term side effects on the urinary tract, while the cesarean section is more often associated with injuries that are easily recognized and repaired during surgery with no long-term impact. Although many attempts have been made to successfully identify those patients who may benefit from a repeated cesarean section, no clinical or ultrasound criteria can predict with certainty the evolution of a trial of labor after a cesarean section.

\section{ACKNOWLEDGMENTS}

\section{Conflict of interest}

The authors declare that there is no conflict of interest.

\section{REFERENCES}

1. Martel, M.-J.; MacKinnon, C. J. No. 155-Guidelines for Vaginal Birth After Previous Caesarean Birth. J Obstet Gynaecol Can 2018, 40 (3), e195-e207.

https://doi.org/10.1016/j.jogc.2018.01.014

2. Osterman, M. J. K. Recent Trends in Vaginal Birth After Cesarean Delivery: United States, 2016-2018. 2020, No. 359,8

3. Tarney, C. M. Bladder Injury During Cesarean Delivery. Curr Womens Health Rev 2013, 9 (2), 70-76. https://doi.org/10.2174/157340480902140102151729

4. Ophir, E.; Odeh, M.; Hirsch, Y.; Bornstein, J. Uterine Rupture during Trial of Labor: Controversy of Induction' Methods. Obstet Gynecol Surv 2012, 67 (11), 734-745. https://doi.org/10.1097/OGX.0b013e318273feeb

5. Ouzounian, J. G.; Miller, D. A.; Hiebert, C. J.; Battista, L. R.; Lee, R. H. Vaginal Birth after Cesarean Section: Risk of Uterine Rupture with Labor Induction. Am J Perinatol 2011, 28 (8), 593-596. https://doi.org/10.1055/s-0031-1275386

6. Stenson, D.; Wallstrom, T.; Sjostrand, M.; Akerud, H.; Gemzell-Danielsson, K.; Wiberg-Itzel, E. Induction of Labor in Women with a Uterine Scar. J Matern Fetal Neonatal Med
2016, 29 (20), 3286-3291. https://doi.org/10.3109/14767058.2015.1123242

7. Shirzad, M.; Shakibazadeh, E.; Rahimi Foroushani, A.; Abedini, M.; Poursharifi, H.; Babaei, S. Effect of "Motivational Interviewing" and "Information, Motivation, and Behavioral Skills" Counseling Interventions on Choosing the Mode of Delivery in Pregnant Women: A Study Protocol for a Randomized Controlled Trial. Trials 2020, 21 (1), 970 https://doi.org/10.1186/s13063-020-04865-3

8. Betran, A. P.; Ye, J.; Moller, A.-B.; Souza, J. P.; Zhang, J Trends and Projections of Caesarean Section Rates: Global and Regional Estimates. BMJ Global Health 2021, 6 (6), e005671. https://doi.org/10.1136/bmjgh-2021-005671

9. Luo, Z.-C.; Liu, X.; Wang, A.; Li, J.-Q.; Zheng, Z.-H.; Guiyu, S.; Lou, T.; Pang, J.; Bai, X.-L. Obstetricians' Perspectives on Trial of Labor after Cesarean (TOLAC) under the Two-Child Policy in China: A Cross-Sectional Study. BMC Pregnancy Childbirth 2021, 21 (1), 89. https://doi.org/10.1186/s12884-021-03559-1

10. Phipps, M. G.; Watabe, B.; Clemons, J. L.; Weitzen, S.; Myers, D. L. Risk Factors for Bladder Injury during Cesarea Delivery. Obstet Gynecol 2005, 105 (1), 156-160. https://doi.org/10.1097/01.AOG.0000149150.93552.78

11. Attanasio, L. B.; Kozhimannil, K. B.; Kjerulff, K. H. Women's Preference for Vaginal Birth after a First Delivery by Cesarean. Birth 2019, 46 (1), 51-60.
https://doi.org/10.1111/birt.12386

12. Fonseca, J. E.; Rodriguez, J. L.; Maya Salazar, D. Validation of a Predictive Model for Successful Vaginal Birth after Cesarean Section. Colomb Med (Cali) 2019, 50 (1), 13-21. https://doi.org/10.25100/cm.v50i1.2521

13. Haumonte, J.-B.; Raylet, M.; Christophe, M.; Mauviel, F; Bertrand, A.; Desbriere, R.; d'Ercole, C. French Validation and Adaptation of the Grobman Nomogram for Prediction an of Vaginal Birth after Cesarean Delivery. J Gynecol Obstet
Hum Reprod 2018, 47 (3), 127-131. https://doi.org/10.1016/j.jogoh.2017.12.002

14. Lipschuetz, M.; Guedalia, J.; Rottenstreich, A.; Novoselsky Persky, M.; Cohen, S. M.; Kabiri, D.; Levin, G. Yagel, S.; Unger, R.; Sompolinsky, Y. Prediction of Vaginal Birth after Cesarean Deliveries Using Machine Learning. Am J Obstet Gynecol 2020, 222 (6), 613.e1-613.e12. https://doi.org/10.1016/j.ajog.2019.12.267

15. Place, K.; Kruit, H.; Tekay, A.; Heinonen, S.; Rahkonen, L. Success of Trial of Labor in Women with a History of Previous Cesarean Section for Failed Labor Induction or Labor Dystocia: A Retrospective Cohort Study. BMC Pregnancy Childbirth 2019, 19 (1), 176. https://doi.org/10.1186/s12884-019-2334-3 


\section{JOURNAL of MEDICINE and LIFE}

16. ACOG Practice Bulletin No. 205: Vaginal Birth After Cesarean Delivery. Obstet Gynecol 2019, 133 (2), e110-e127. https://doi.org/10.1097/AOG.0000000000003078

17. Practice Bulletin No. 184: Vaginal Birth After Cesarean Delivery. Obstet Gynecol 2017, 130 (5), e217-e233. https://doi.org/10.1097/AOG.000000000000

18. Sentilhes, L.; Vayssière, C.; Beucher, G.; DeneuxTharaux, C.; Deruelle, P.; Diemunsch, P.; Gallot, D.; Haumonté, J.-B.; Heimann, S.; Kayem, G.; Lopez, E, Parant, O.; Schmitz, T.; Sellier, Y.; Rozenberg, P.; d'Ercole, C. Delivery for Women with a Previous Cesarean: Guidelines for Clinical Practice from the French College of Gynecologists and Obstetricians (CNGOF). Eur J Obstet Gynecol Reprod Biol 2013, 170 (1), 25-32.

https://doi.org/10.1016/j.ejogrb.2013.05.015

19. Beucher, G.; Dolley, P.; Lévy-Thissier, S.; Florian, A.; Dreyfus, M. Maternal benefits and risks of trial of labo versus elective repeat caesarean delivery in women with a previous caesarean delivery]. J Gynecol Obstet Biol Reprod (Paris) 2012, 41 (8), 708-726.

https://doi.org/10.1016/j.jgyn.2012.09.028

20. Phillips, B.; Holzmer, S.; Turco, L.; Mirzaie, M.; Mause, E.; Mause, A.; Person, A.; Leslie, S. W.; Cornell, D. L.; Wagner, M.; Bertellotti, R.; Asensio, J. A. Trauma to the Bladder and Ureter: A Review of Diagnosis, Management, and Prognosis. Eur J Trauma Emerg Surg 2017, 43 (6), 763-773. https://doi.org/10.1007/s00068-017-0817-3

21. Tazion, S.; Hafeez, M.; Manzoor, R.; Rana, T. Ultrasound Predictability of Lower Uterine Segment Cesarean Section Scar Thickness. J Coll Physicians Surg Pak 2018, 28 (5), 361-364.

https://doi.org/10.29271/jcpsp.2018.05.36

22. di Pasquo, E.; Kiener, A. J. O.; DallAsta, A.; Commare, A.; Angeli, L.; Frusca, T.; Ghi, T. Evaluation of the Uterine Scar Stiffness in Women with Previous Cesarean Section by Ultrasound Elastography: A Cohort Study. Clin Imaging 2020, 64, 53-56.

https://doi.org/10.1016/j.clinimag.2020.03.006

23. Rajasekar, D.; Hall, M. Urinary Tract Injuries during Obstetric Intervention. BJOG: An International Journal of Obstetrics \& Gynaecology 1997, 104 (6), 731-734 https://doi.org/10.1111/j.1471-0528.1997.tb11986.x

24. Roth, J. D.; Casey, J. T.; Whittam, B. M.; Szymanski, K. M.; Kaefer, M.; Rink, R. C.; Schubert, F. P.; Cain, M. P.; Misseri, R. Complications and Outcomes of Pregnancy and Cesarean Delivery in Women With Neuropathic Bladder and Lower Urinary Tract Reconstruction. Urology 2018, 114, 236-243. https://doi.org/10.1016/j.urology2017.11.052

25. Fishel Bartal, M.; Sibai, B. M.; Ilan, H.; Fried, M.; Rahav, R.; Alexandroni, H.; Schushan Eisan, I.; Hendler, I. Trial of Labor after Cesarean (TOLAC) in Women with Premature Rupture of Membranes. J Matern Fetal Neonatal Med 2020, 33 (17), 2976-2982.

https://doi.org/10.1080/14767058.2019.1566312
26. Tähtinen, R. M.; Cartwright, R.; Tsui, J. F.; Aaltonen, R. L.; Aoki, Y.; Cárdenas, J. L.; El Dib, R.; Joronen, K. M.; Al Juaid, S.; Kalantan, S.; Kochana, M.; Kopec, M.; Lopes, L. C.; Mirza, E.; Oksjoki, S. M.; Pesonen, J. S.; Valpas, A.; Wang, L.; Zhang, Y.; Heels-Ansdell, D.; Guyatt, G. H.; Tikkinen, K. A O. Long-Term Impact of Mode of Delivery Tikkinen, K. A. O. Long-Term Impact of Mode of Defive
on Stress Urinary Incontinence and Urgency Urinary on Stress Urinary Incontinence and Urgency Urinary Uncontinence: A Systematic Urol 2016, 70 (1), 148-158.
https://doi.org/10.1016/j.eururo.2016.01.037

27. Dagher, A. P.; Fishman, E. K. Uterine and Bladder Rupture during Vaginal Delivery in a Patient with a Prio Cesarean Section: Case Report. Urol Radiol 1992, 14 (3), 200-201. https://doi.org/10.1007/BF02926930

28. Cahill, A. G.; Stout, M. J.; Stamilio, D. M.; Odibo, A. O.; Peipert, J. F.; Macones, G. A. Risk Factors for Bladder Injury in Patients with a Prior Hysterotomy. Obstet Gynecol 2008, $112(1), 116-120$.

https://doi.org/10.1097/AOG.0b013e31817946f4

29. El-Tabey, N. A.; Ali-El-Dein, B.; Shaaban, A. A.; ElKappany, H. A.; Mokhtar, A. A.; El-Azab, M.; Kheir, A. Kappany, H. A.; Mokhtar, A. A.; El-Azab, M.; Kheir, A. A. Urological Trauma after Gynecological and Obstetric https://doi.org/10.1080/00365590600589476

30. Ho, S.-Y.; Chang, S.-D.; Liang, C.-C. Simultaneous Uterine and Urinary Bladder Rupture in an Otherwise Successful Vaginal Birth After Cesarean Delivery. Journal of the Chinese Medical Association 2010, 73 (12), 655-659 https://doi.org/10.1016/S1726-4901(10)70143-X

31. Lee, J. Y.; Cass, A. S. Spontaneous Bladder and Uterine Rupture with Attempted Vaginal Delivery after Cesarean Section. J Urol 1992, 147 (3), 691-692.

https://doi.org/10.1016/s0022-5347(17)37352-4

32. Vaginal delivery doubles the risk of stress incontinence compared to caesarean section https://www.sciencedaily. $\mathrm{com} /$ releases/2016/02/160223074738.htm (accessed 2021-05-13)

33. Ozdemir, E. Ozturk, U; Celen, S.; Sucak, A.; Gunel, M.; Guney, G.; Imamoglu, M. A.; Danisman, A. N. Urinary Complications of Gynecologic Surgery: Iatrogenic Urinary Tract System Injuries in Obstetrics and Gynecology Operations. Clin Exp Obstet Gynecol 2011, 38 (3), 217-220

34. Dauleh, W.; Sakka, M. A.; Shahata, M. Urinary Tract Injuries During Caesarean Section. Qatar Medical Journal 2006, 2006 (2), 8. https://doi.org/10.5339/qmj.2006.2.8

35. Cahill, A. G.; Stamilio, D. M.; Odibo, A. O.; Peipert, J. F.; Ratcliffe, S. J.; Stevens, E. J.; Sammel, M. D.; Macones, G. A. Is Vaginal Birth after Cesarean (VBAC) or Elective Repeat Cesarean Safer in Women with a Prior Vaginal Delivery? Am J Obstet Gynecol 2006, 195 (4), 1143-1147.

https://doi.org/10.1016/j.ajog.2006.06.045
36. Lua, L. L.; Evans, T.; Gomez, N. Simultaneous Uterine and Bladder Rupture Following Successful Vaginal Birth After Cesarean Delivery: Laparoscopic Repair of Defect. J Minim Invasive Gynecol 2017, 24 (2), 329-332.

https://doi.org/10.1016/j.jmig.2016.10.002

37. Manidip, P.; Soma, B. Cesarean Bladder Injury Obstetrician's Nightmare. J Family Med Prim Care 2020, 9 (9), 4526-4529. https://doi.org/10.4103/jfmpc.jfmpc_586_20

38. Tulandi, T.; Agdi, M.; Zarei, A.; Miner, L.; Sikirica, V. Adhesion Development and Morbidity after Repeat Cesarean Delivery. Am J Obstet Gynecol 2009, 201 (1), 56.e1-6. https://doi.org/10.1016/j.ajog.2009.04.039

39. Uyanikoglu, H.; Karahan, M. A.; Turp, A. B.; Agar, M.; Tasduzen, M. E.; Sak, S.; Erdal Sak, M. Are Multiple Repeated Cesarean Sections Really as Safe? J Matern Fetal Neonatal Med 2017, 30 (4), 482-485.

https://doi.org/10.1080/14767058.2016.1175426

40. Takai, I. U.; Abubakar, A. Combined Uterine and Urinary Bladder Rupture: An Unusual Complication of Obstructed Labor in a Primigravida. Int $\mathrm{J}$ Womens Health 2016, 8, 295-298. https://doi.org/10.2147/IJWH.S10435

41. Filip, L.; Duică, F.; Prădatu, A.; Crețoiu, D.; Suciu, N.; Cretoiu, S. M.; Predescu, D.-V.; Varlas, V. N.; Voinea, S.-C. Crețoiu, S. M.; Predescu, D.-V.; Varlas, V. N.; Voinea, S.-C. Analysis on Etiopathogenesis and Therapeutic Approaches. Medicina (Kaunas) 2020, 56 (9).

https://doi.org/10.3390/medicina56090460

42. Sharma, N.; Thiek, J. L.; Sialo, S.; Ahanthem, S. S. Concomitant Vesicouterine Rupture with Avulsion of Ureter: A Rare Complication of Vaginal Birth after Cesarean Section. J Clin Diagn Res 2016, 10 (3), QD07-QD08. https://doi.org/10.7860/JCDR/2016/17406.7503

43. Gilmour, D. T.; Vallis, T. M.; Lee, W.; Colford, D.; Reardon, E. Minimizing the Urological and Psychological Morbidity of Urinary Tract Fistulae From VBAC. Journal of Obstetrics and Gynaecology Canada 2006, 28 (2), 132-135. https://doi.org/10.1016/S1701-2163(16)32060-6

44. López-Carpintero, N.; de la Fuente-Valero, J.; Salazar-Arquero, F.J.; Hernández-Aguado, J.J. [Great vesicovaginal fistula after normal vaginal delivery in a developed country]. Ginecol Obstet Mex 2015, 83 (12), 798-802.

45. Wise, M. R.; Sadler, L.; Shorten, B.; van der Westhuizen, K.; Shorten, A. Birth Choices for Women in a "Positive Birth after Caesarean" Clinic: Randomised Trial of Alternative Shared Decision Support Strategies. Aust N Z J Obstet Gynaecol 2019, 59 (5), 684-692. https://doi.org/10.1111/ajo.12955 